Jahrbuch für Geschichte Lateinamerikas

Anuario de Historia de América Latina

$58|2021| 234-269$

Marco Alejandro Sifuentes Solís

Jorge Refugio García Díaz

Alejandro Acosta Collazo

Universidad Autónoma de Aguascalientes

De Alemania a México: Samuel Chávez y la gimnasia rítmica del Instituto Dalcroze,

1912-1922
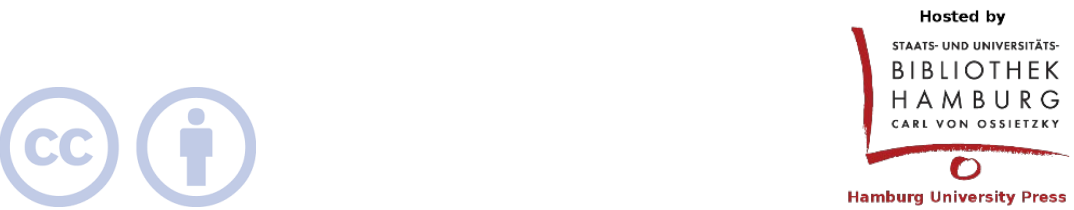

Except where otherwise noted, this article is licensed under a Creative Commons Attribution 4.0 International license (CC BY 4.0)

https://doi.org/10.15460/jbla.58.161 


\title{
De Alemania a México: Samuel Chávez y la gimnasia rítmica del Instituto Dalcroze, 1912-1922
}

\author{
Marco Alejandro Sifuentes Solís \\ Jorge Refugio García Díaz \\ Alejandro Acosta Collazo ${ }^{1}$
}

\begin{abstract}
The main objective of this article is to make known to the community of historians, especially architecture historians, a little explored facet of the architect Samuel Chávez (a native of the city of Aguascalientes but whose professional development was centered in Mexico City), consisting of the interest he maintained in the relationship between architecture, dance and music. To this end, the text offers historical evidence and arguments based both on the interpretation of a corpus of documents from his personal archive (which as far as is known has not been worked on by the specialized historiography), as on the hemerography of the time and the current bibliography. Beyond what Raquel Tibol (1984) affirmed, in the sense of considering Samuel Chávez as one of the forerunners of modern dance in Mexico, our contribution consists of documenting, in a contextualized way, the meeting point of the architect with the key pedagogical center of the movements for the reform of life: the Jaques Dalcroze Institute of Rhythmics, located in the German garden city of Hellerau, which was a turning point in the professional career of Chávez as he freed himself from the bonds of his former Beaux-arts training, and thus linked him to the European avant-garde of the moment. Our article only focuses on the period 1912-1922.
\end{abstract}

Keywords: Rhythmic Gymnastics, Garden City, Hellerau, Pedagogy, Pneumaphone.

Resumen. - El objetivo central de esta entrega es dar a conocer a la comunidad de historiadores, en especial a los historiadores de la arquitectura, una faceta poco explorada del arquitecto Samuel Chávez (oriundo de la ciudad de

\footnotetext{
1 Este texto es un subproducto del Proyecto PIA 18-1, "El cuerpo en movimiento y el ritmo vital. Arquitectura, danza y música en Samuel Chávez (1912-1927)”, financiado por la Universidad Autónoma de Aguascalientes y desarrollado entre 2018 y 2020. Los autores desean dejar constancia del inestimable apoyo de Eduwiges Hernández Becerra como auxiliar de investigación.
} 
Aguascalientes pero cuyo desarrollo profesional tuvo como centro la Ciudad de México), consistente en el interés que mantuvo por la relación entre arquitectura, danza y música; a tal efecto, el texto ofrece evidencia histórica y argumentos fundados tanto en la interpretación de un corpus de documentos de su archivo personal, que hasta donde se sabe no ha sido trabajado por la historiografía especializada, como en hemerografía de la época y fuentes secundarias actuales. Más allá de lo afirmado por Raquel Tibol (1984), en el sentido de considerar a Samuel Chávez como uno de los precursores de la danza moderna en México, nuestra aportación consiste en documentar, de manera contextualizada, el punto de encuentro de nuestro arquitecto con el centro pedagógico clave de los movimientos para la reforma de la vida: el Instituto de Rítmica de Jaques Dalcroze, sito en la ciudad-jardín alemana de Hellerau, lo que supuso una inflexión en la trayectoria profesional de Chávez al liberarse de las ataduras de su formación Beaux-arts y vincularse a la vanguardia europea del momento. Nuestra entrega sólo se centra en el período 1912-1922.

Palabras clave: Gimnasia rítmica, ciudad-jardín, Hellerau, pedagogía, pneumáfono.

\section{Introducción}

En 1912, comisionado por el gobierno de Francisco I. Madero, el arquitecto Samuel Chávez Lavista emprendió un largo viaje a la ciudad de Dresde, Alemania, para participar como delegado en el IV Congreso Internacional de Instrucción Artística, Dibujo y Arte Aplicado. Ahí, a pocos kilómetros de esta ciudad, se encontraba la ciudad-jardín de Hellerau, la cual albergó una de las experiencias vanguardistas más interesantes en la Europa de pre-guerra: la provincia pedagógica del Instituto Dalcroze de Rítmica. El 15 de agosto de ese año, la organización del congreso llevó a los participantes a Hellerau, en donde Chávez atestiguó una demostración de gimnasia rítmica que cambiaría, en muchos sentidos, su vida.

A raíz de ese crucial año de 1912, Samuel comenzó a interesarse por la práctica de la gimnasia rítmica y sus implicaciones sobre la salud física, mental y espiritual del cuerpo, que ya había explorado en Aguascalientes, México, en un proyecto urbanístico de 1901: el Plano de las Colonias. En este proyecto ensayó toda una pedagogía espacial de lo corporal, interés que fue compartido por su hermano Ezequiel A. 
Chávez, uno de los primeros autores mexicanos que visualizaron y llevaron a cabo reflexiones sobre la corporalidad. ${ }^{2}$

Por allá del año 1910, la vanguardia de la gimnasia rítmica estaba representada por el ginebrino (aunque nacido en Austria) Émile JaquesDalcroze, que había llevado su instituto desde Ginebra a Hellerau, primera ciudad-jardín de Alemania y primera construida en toda Europa fuera de las de Letchworth y Welwyn en Inglaterra. Para Chávez, su designación como delegado al congreso no pudo llegar en mejor momento. Así, este artículo tiene un doble propósito: primero, documentar los pasos que condujeron a Samuel Chávez a su encuentro con Dalcroze y la propuesta vanguardista de la gimnasia rítmica; y segundo, glosar un escrito por él publicado sobre esta disciplina, que le sirvió para dar fundamento teórico-práctico a su intención de fomentar la educación artística a su regreso a México, a partir de la práctica personal y pedagógica de esa gimnasia. A tal efecto, se consultaron, analizaron e interpretaron, mediante una metodología hermenéutica, documentos diversos provenientes de archivos públicos y privados, físicos y electrónicos, así como fuentes secundarias.

El objeto de estudio se encuadra principalmente dentro de los estudios sobre el ritmo y los aspectos pedagógicos derivados de la práctica de la gimnasia rítmica aplicados a la educación artística, en la línea de trabajos como los de Jaques-Dalcroze, ${ }^{3}$ Brozas, ${ }^{4}$ Capistrán, ${ }^{5}$ Del

\footnotetext{
2 Sergio López Ramos, citado por Norma Delia Durán Amavizca, La pedagogía de lo corporal y de la salud. Una filosofía para vivir. Historia de las ideas psicológicas y pedagógicas de Sergio López Ramos, México: UNAM, 2011 (tesis doctoral), p. 187.

3 Émile Jaques-Dalcroze, The Eurhythmics of Jaques Dalcroze, London: Constable \& Company Ltd., 1912; y Dalcroze, La rythmique, Lausanne: Jobin \& Cie. (vol. 1), 1916.

${ }^{4}$ María Paz Brozas, "Contact Improvisation. Danza, acrobacia y pedagogía corporal": Actas del I Congreso de la Asociación Española de Ciencias del Deporte I, Cáceres: Universidad de Extremadura, 2000, pp. 309-316; y Brozas, "Cuerpo e imagen en el encuentro de la danza con otras artes": Brozas (ed.), Cuerpo, imagen y expresión. Entre la creación artística y la intervención educativa, España Universidad de León, 2006, pp. 59-75.

${ }^{5}$ Raúl Capistrán, "Retomando el enfoque de Émile Jaques-Dalcroze en la formación del profesional de la música": Escena. Revista de las artes, 78: 2 (2019), pp. 37-55.
} 
Bianco, ${ }^{6}$ Durán Amavizca, ${ }^{7}$ González Belmonte, ${ }^{8}$ Gálvez, ${ }^{9}$ Mancebo, 10 Schnebly-Black, ${ }^{11}$ Sifuentes, ${ }^{12}$ Spector, ${ }^{13}$ Vasconcelos, ${ }^{14}$ Michon, ${ }^{15}$ Povedano, ${ }^{16}$ y Quesada. ${ }^{17}$ Esta historiografía enfatiza los aspectos artísticos y pedagógicos de la gimnasia rítmica y la corporalidad, por contraposición a la perspectiva de una gimnasia más física, en la línea

6 Silvia del Bianco, "Jaques-Dalcroze": Maravillas Díaz / Andrea Giráldez (eds.), Aportaciones teóricas y metodológicas a la educación musical, Barcelona: Graó, 2007, pp. 24-32.

7 Durán Amavizca, La pedagogía.

8 Julia González Belmonte, La aplicación del método Dalcroze en las enseñanzas elementales del Conservatorio Profesional de Música 'Tomás de Torrejón y Velasco' de Albacete. La rítmica vivencial de los conceptos del lenguaje musical, España: UNED, 2013 (tesis doctoral).

9 María Auxiliadora Gálvez Pérez, Materia activa. La danza como campo de experimentación para una arquitectura de raíz fenomenológica, España: Universidad Politécnica de Madrid, 2012 (tesis doctoral).

10 José Agustín Mancebo, El cuerpo ritualizado, Universidad Autónoma de Barcelona, 2007, en línea: https://www.researchgate.net/publication/ 349506097_El_cuerpo_ritualizado [09-08-2021].

11 Julia Schnebly-Black, "Reseña del libro 'Rhythm and Life. The Work of Emile Jaques-Dalcroze', de Irwin Spector": Notes, 49: 1 (1992), pp. 161-164.

12 Marco Alejandro Sifuentes Solís, "Una pedagogía espacial de lo corporal. Samuel Chávez y el Plano de las Colonias (1901)": Journal of Humanities and Social Sciences, 22: 3 (2017), pp. 21-32.

13 Irwin Spector, "Bring Back Dalcroze": American Music Teacher, 21: 6 (1972), pp. 19-21.

14 José Vasconcelos, "Pitágoras. Una teoría del ritmo": Christopher Domínguez Michel (ed.), Los retornos de Ulises. Una antología de José Vasconcelos, México: Fondo de Cultura Económica, 2010, pp. 121-127.

15 Pascal Michon, "Sobre el concepto de episteme del ritmo": Rhuthmos, 15 de abril de 2019, pp. 1-8, en línea: http://rhuthmos.eu/spip.php?article2270 [22-032021]; y Michon, "Ritmo, ritmanálisis, ritmología. Un ensayo del estado de la cuestión": Rhuthmos, 16 de abril de 2019, pp. 1-17, en línea: http://rhuthmos.eu/spip.php?article2340 [22-03-2021].

16 Elisa Povedano Marrugat, Arte industrial y renovación pedagógica en España e Iberoamérica. Identidad y vanguardia (1826-1950), España: Universidad Carlos III de Madrid, 2002 (tesis doctoral).

17 Fernando Quesada, La caja mágica. Cuerpo y escena, Barcelona: Fundación Caja de Arquitectos, 2005. 
de Chávez González, ${ }^{18}$ Kumlien y André. ${ }^{19}$ Y a efectos de contextualización del movimiento de las ciudades-jardín europeas, trabajos como los de Guerrand, ${ }^{20}$ Nerdinger, ${ }^{21}$ Ramos Gorostiza, ${ }^{22}$ Sevilla Buitrago, ${ }^{23}$ y García Roig. ${ }^{24}$

El texto se organiza en una introducción, cinco apartados y las conclusiones. Después de la introducción, se ofrece, en un primer apartado, una breve semblanza del arquitecto Samuel Chávez; luego, en el segundo, vienen las circunstancias de la partida de Chávez a Dresde; posteriormente, en el tercero, se analiza lo que el Instituto de Rítmica representó para la cultura europea de pre-guerra y para Chávez mismo; en el cuarto, se revisa el potencial pedagógico de la gimnasia rítmica; y en el quinto, se glosa un ensayo de Chávez sobre gimnasia rítmica en el contexto de las políticas públicas sobre la educación artística en México.

\section{¿Quién fue Samuel Chávez?}

Integrante de una de las familias más reconocidas y respetadas del Aguascalientes decimonónico, Samuel Chávez Lavista ${ }^{25}$ nació en esa ciudad el 26 de septiembre de 1867 y murió a la edad de 62 años en la

18 Mónica Lizbeth Chávez González, La introducción de la educación física en México. Representaciones sobre el género y el cuerpo, 1882-1928, México: El Colegio de San Luis, 2006 (tesis de maestría).

${ }^{19}$ L. G. Kumlien / Emile André, La gimnasia sueca. Manual de gimnasia racional al alcance de todos y para todas las edades, París: Imprenta de la Vda de C. Bouret, 1909.

20 Roger-Henri Guerrand, "Sobre los orígenes del movimiento de las ciudadesjardines en Europa": Ciudades, 6 (2000-2001), pp. 17-20.

21 Winfriend Nerdinger, Deutscher Werkbund 1907-2007. 100 años de arquitectura y diseño en Alemania, Alemania: Instituto para las Relaciones Internacionales de Alemania / Museo de Arquitectura de la Universidad de Técnica de Múnich, 2015.

22 José Luis Ramos Gorostiza, "El descontento frente a la ciudad industrial. Reformismo social y 'ciudad jardín' en España, 1900-1923”: Revista de Historia Industrial, 17: 37 (2008), pp. 85-122.

23 Álvaro Sevilla Buitrago, "Großstadtkultur. La cuestión de la gran ciudad en la Alemania guillermina": Ciudades, 8 (2004), pp. 201-227.

24 José Manuel García Roig, Heinrich Tessenow. Pensamiento utópico, germanidad, arquitectura, España: Universidad de Valladolid, 2002.

25 El acta de bautizo en Family Search, en línea: https://familysearch.org/ ark:/61903/1:1:KTRD-7D8 [28-06-2021], certificate 1367, page 37, FHL microfilm 298,558. 
Ciudad de México, en 1929. Fue el primer hijo del matrimonio del Dr. Ignacio Toribio Chávez Acosta, exgobernador de Aguascalientes, y Guadalupe Rosa Lavista Rebollar. ${ }^{26}$ Del resto de sus hermanos y hermanas, destacó el segundo de los vástagos, Ezequiel Adeodato (1868-1946), personaje de relevancia nacional e internacional, pues cultivó la filosofía, la psicología, la pedagogía y la historia, y detentó cargos de primer nivel en la administración de Porfirio Díaz y la Universidad Nacional. 27

Después de iniciar los estudios básicos en su ciudad natal, Samuel los concluyó en la Ciudad de México y luego ingresó a la Escuela Nacional Preparatoria; más tarde, en 1894, se graduó como ingeniero-arquitecto en la Escuela Nacional de Bellas Artes (ENBA). ${ }^{28}$ Asimismo, fue maestro de dicha institución, en donde impartió diversas cátedras, entre ellas aquella de la que fue titular, a partir de 1903, denominada Estilos de Ornamentación en los Edificios. ${ }^{29}$

Posteriormente, ya con su título en mano, transcendió en su tierra natal por trazar el Plano de las Colonias en 1901, trabajo que lo encumbró como uno de los precursores del urbanismo moderno en México. Sin embargo, la importancia de Samuel Chávez a nivel nacional no radica en lo anterior, sino en que fue el autor y director del proyecto de buena parte de las obras de reforma del vetusto edificio del Colegio de San Ildefonso (junto con Manuel Torres Torija), ocupado por la Escuela Nacional Preparatoria, y autor y director de obra de su anfiteatro (después llamado Anfiteatro Bolívar), ${ }^{30}$ lugar, cabe señalar,

26 Biblioteca Pública Central Centenario-Bicentenario, Fondo Alejandro Topete del Valle, Acta de Matrimonio de Ignacio T. Chávez, Exp. 568, 1866.

27 Para estudiar la vida y obra de Ezequiel A. Chávez, se recomienda su libro ¿De dónde venimos y a dónde vamos?, México: El Colegio Nacional, 1946. Asimismo, también véase Daniel de Lira Luna, "La biblioteca personal de don Ezequiel A. Chávez": Biblioteca Universitaria, 9: 2 (2006), pp. 133-143.

${ }_{28}$ Archivo Particular Samuel Chávez Lavista [en adelante APSChL], en proceso de catalogación.

29 Dicho nombramiento, en APSChL, en proceso de catalogación. Asimismo, véase Archivo General de la Nación [en adelante AGN], Instrucción Pública y Bellas Artes, vol. 17, exp. 10, 8 fs., 1905, con el fin de verificar que Samuel Chávez ostentaba dicha cátedra.

30 Dichos proyectos se llevaron a cabo entre 1902 y 1910; ver Samuel Chávez, Informe acerca de las obras de ampliación de la Escuela Nacional Preparatoria, México: Tipografía y Litografía de Müller Hermanos, 1911. 
en donde el 22 de septiembre de 1910 fue inaugurada, en solemne ceremonia, la Universidad Nacional. ${ }^{31}$ De este modo, el anfiteatro de Samuel Chávez no sólo está ligado al patrimonio universitario, sino al patrimonio cultural de la nación por la circunstancia de celebrarse ahí aquel acontecimiento fundamental para el país.

En resumen, varias fueron las etapas que marcaron la vida y trayectoria de este personaje: desde su nacimiento en la ciudad de Aguascalientes hasta su partida a la Ciudad de México (1867-1877), a donde se trasladó su familia; 32 pasando por el término de su educación elemental superior, hasta la preparatoria (1878-1885); su paso por la ENBA y sus primeros años en el ejercicio de la profesión (1886-1910), período durante el cual se tituló y emprendió en la capital del país sus primeros proyectos arquitectónicos y dirección de obra, diseñando las casas de su tío, el mundialmente conocido Jesús F. Contreras (1900) y de su hermano Ezequiel (1901), 33 entre otros; y finalmente, el punto de inflexión que en su vida profesional representó el arranque, en 1912, de una fase que lo llevó a experimentar, por el resto de sus días, con los campos disciplinares de la euritmia (en particular con la gimnasia

31 Véase la crónica en: La Universidad Nacional de México, 1910, México: UNAM, 1985, p. 104.

32 Dice Leticia Chávez, hija de Ezequiel: "Mi abuelo había determinado venirse a México, para procurar una mejor educación de sus hijos". Por lo tanto, "a principios de febrero de 1877, cuando tenía yo [Ezequiel] ocho años y poco más de cuatro meses: mi madre iba a partir con nosotros, sus hijos: mi hermano mayor [Samuel], mi hermana, nuestra dulce Esther que a distancia de 3 años siete meses me seguía; mi hermano menor, David, que sólo tenía entonces 2 años y medio y yo, para reunirse en México con nuestro padre". Véase Leticia Chávez, Recordando a mi padre, México: Asociación Civil Ezequiel A. Chávez, 1964 (vol. 1), p. 47.

33 En Aguascalientes, la casa de Juan Douglas (1901); la casa de Enrique Escobedo (1902); la ferretería La Perla (1904), hoy Museo de Arte Contemporáneo; entre otros proyectos y obras. Los proyectos de estas obras se pueden ver en: APSChL, en proceso de catalogación. 
rítmica) ${ }^{34}$ y la música, combinando tales inclinaciones con la función pública como inspector de escuelas de dibujo y trabajos manuales. 35

\section{La comisión a Dresde, 1912}

Francisco I. Madero fue presidente de México a partir del 6 de noviembre de 1911. Su gobierno sólo duró un año y tres meses. Entre otras disposiciones, proyectó una nueva estrategia para impulsar el campo, impulsó la cultura y, sobre todo, intentó abrir escuelas por todo el país. ${ }^{36}$

Es en este contexto político donde, influido por el pensamiento de su época y las reflexiones pedagógicas de su hermano Ezequiel, Samuel Chávez no sólo manifestó un inusitado interés por la educación artística, sino que desarrolló habilidades relacionadas con el dibujo y su enseñanza. Las buenas relaciones que mantuvo con algunos miembros de la clase política le valieron para convencer a las autoridades del nuevo gobierno de la conveniencia de prepararse en estas materias, a efectos de acompasar sus enseñanzas con las tendencias más renovadoras del momento. Bajo esta lógica, Samuel se dirigió, mediante una carta, al presidente Madero el 16 de noviembre de 1911, con el propósito de pedirle una entrevista "para manifestarle datos de suma importancia". ${ }^{37}$ Todo parece indicar que en la entrevista se abordó la conveniencia de asistir al IV Congreso Internacional de Instrucción Artística, Dibujo y Arte Aplicado, en Dresde, Alemania.

Al siguiente año, Samuel Chávez —después de convencer al presidente- viajó a dicha ciudad comisionado por el gobierno

\footnotetext{
34 La gimnasia rítmica "es sólo una aplicación de un principio mucho más amplio", es "un modo particular de ejercicio físico" que "no es un mero refinamiento de la danza, ni un método mejorado de enseñanza musical, sino un principio que debe tener efecto en cada parte de la vida". Dicho principio, y el método total que lo incorpora, se denomina en el método Dalcroze: "Eurhythmics". Véase John W. Harvey, "Prefacio": Jaques-Dalcroze, The Eurhythmics, p. 5.

35 El nombramiento en: AGN, Instrucción Pública y Bellas Artes, vol. 292, exp. 25, 12 fs., 1913.

36 Enrique Krauze, Francisco I. Madero. Místico de la libertad, México: Fondo de Cultura Económica, 2002, pp. 79-93. Véase también Felipe Ávila / Pedro Salmerón, Historia breve de la Revolución mexicana, México: Siglo XXI Editores, 2016, pp. 102-121.

${ }^{37}$ AGN, Francisco I. Madero, caja 69, exp. 1, fs. 48, 1911.
} 
mexicano para asistir como delegado al congreso antes mencionado. La comisión, apareció el 26 de julio de 1912 en el Diario Oficial. 38

El nuevo gobierno de Francisco I. Madero comprendió la importancia de esta comisión, dado que en su comparecencia ante el primer período del $26^{\circ}$ Congreso de la Unión, con motivo de su primero y último informe de gobierno del 16 de septiembre de 1912, consignó que "La República estuvo representada por una delegación [...] en el Congreso Internacional de instrucción artística, dibujo y arte aplicado, en Dresden". ${ }^{39}$ Es probable que en la decisión de comisionar a Samuel a Dresde influyera Alberto J. Pani, quien a la sazón despachaba como subsecretario de Instrucción Pública y Bellas Artes en el gobierno de Madero, pues además de ser su coetáneo, conocía el interés que Chávez profesaba por la instrucción artística y el dibujo; e, incluso, cultivaron cierta amistad e intereses comunes. ${ }^{40}$

Si bien el presidente Madero no mencionó el nombre del delegado, la comisión a Dresde también fue confirmada por el informe preliminar del evento (que obra en nuestro poder), el cual presenta un ex libris de Samuel Chávez. ${ }^{41}$ Dicho informe, que por disposiciones del Congreso

38 Diario Oficial (26 de julio de 1912), p. 297. Agradecemos al Dr. Jorge Gayón esta información.

39 Esta información en el web site 500 años de México en Documentos, en línea: http://www.biblioteca.tv/artman2/publish/index.shtml [09-08-2021]; consúltese "Discurso de Francisco I. Madero al abrir las sesiones ordinarias del Congreso", 1 de abril de 1912; y "Discurso de Francisco I. Madero al abrir las sesiones ordinarias del Congreso", 16 de septiembre de 1912, en línea: http://www.biblioteca.tv/artman2/publish/1912_213/Discurso_de_Francisco_I _Madero_al_abrir_las_sesion_1263.shtml [09-08-2021].

40 Para entonces, el secretario de Instrucción Pública y Bellas Artes era José María Pino Suárez. Pani aceptó el cargo de subsecretario de este ministerio el 21 de noviembre de 1911 y permaneció en él hasta su renuncia por diferencias con Pino Suárez, entre agosto y septiembre de 1912. Como subsecretario, junto con Samuel, propuso la fundación de Academias de Artes Industriales para Obreros, lo que explicaría su interés para la asistencia de Samuel como delegado al congreso de Dresde. Véase Óscar Flores Torres, "Autoexilio, revolución y arte. El caso del mexicano Alberto J. Pani, 1913-1932": XII Jornadas Interescuelas / Departamentos de Historia, Argentina: Universidad Nacional del Comahue, 2009, pp. 3-4.

41 Ver "Vierter Internationaler Kongress für Kunstunterricht, Zeichnen und angewandte Kunst, herausgegeben von der Kongressleitung“, Dresden, 1912, con 
sería enviado a los delegados de cada país el primero de julio, contiene las normas para la celebración y desarrollo del evento, el programa general, las ponencias junto con un breve resumen en tres idiomas, así como información general relativa a precios, agencias de viajes, hospedaje, alimentación y transporte, sin dejar de lado información útil a los congresistas. Samuel sólo acudió con la representación del gobierno mexicano, mas no presentó ponencia.

El delegado español José Garnelo y Alda informó, en la Memoria preparada para el gobierno de su país, que previo a este congreso se realizaron tres ediciones anteriores, en París (1900), Berna (1904) y Londres (1908). El primer congreso fue "de organización y de orden", el segundo "de orientación y fe en los nuevos principios pedagógicos", el tercero "de propaganda y extensión general", mientras que el cuarto, que fue el de Dresde (1912), se consideró "de confirmación científica en la orientación de sus ideales". Agregó que fueron presentados 56 comunicaciones e informes, divididos en dos secciones: la de las escuelas de enseñanza general y la de las escuelas de arte y profesionales. ${ }^{42}$ No es difícil imaginar en cuál sección Samuel Chávez debió participar, codeándose con grandes personalidades de su tiempo, como Hermann Muthesius y Henry van de Velde, quienes asistieron, respectivamente, como Geheimer Regierungsrat (miembro del Ministerio del Interior) y director de la Großherzoglichen Sächsischen Kunstgewerbschule (Gran Escuela Ducal Sajona de Arte). ${ }^{43}$

Los organizadores del evento sugirieron que toda la gestión se hiciera a través de la sucursal en Dresde de la famosa compañía Thomas Cook e Hijo, propiedad original de quien es considerado el "padre del turismo" y de las agencias de viajes. ${ }^{44}$ No obstante, lo más seguro es que Chávez, con algunas escalas intermedias, haya hecho el viaje Nueva York-Bremen (llegando por el puerto de Bremerhaven) a bordo de uno de los más grandes, rápidos y lujosos transatlánticos de entonces. Con

ex libris de Samuel Chávez en portada y contraportada, APSChL, en proceso de catalogación.

42 José Garnelo y Alda, „Memoria” del IV Congreso Internacional para la Enseñanza del Dibujo y de las Artes Aplicadas a la Industria”: Por el Arte. Gaceta de la Asociación de Pintores y Escultores, 1: 5 (1913), p. IX.

43 “Vierter Internationaler Kongress", pp. 9 y 76.

44 Louis Turner / John Ash, La horda dorada. El turismo internacional y la periferia del placer, Madrid: Endymion, 1991, pp. 73-86. Véase también "Vierter Internationaler Kongress", p. 69. 
la documentación disponible, se puede inferir que la travesía la hizo en el SS Kronprinzessin Cecilie, perteneciente al grupo de paquebotes alemanes de pasajeros de la serie Kaiser, y no en el Wilhelm Kaiser der Grosse ${ }^{45}$ contrastando la fecha de ingreso de Samuel a Estados Unidos por Nuevo Laredo, el mencionado 26 de julio, ${ }^{46}$ y la de partida del primer navío, hacia finales de ese mismo mes.

Después de la travesía por mar y tierra, Samuel se trasladó a la sede del congreso en Dresde, y para el día 15 de agosto, exactamente a la mitad del evento, los organizadores programaron una visita a Hellerau (primera ciudad-jardín alemana y de toda Europa continental), ${ }^{47}$ a los talleres alemanes de Schmidt y al precozmente famoso Instituto de Rítmica (en donde, adicionalmente, estaba prevista una demostración en la sala de la escuela). ${ }^{48}$ Desde luego, Chávez hizo ese recorrido y así lo confirma un ensayo escrito y dado a la imprenta en 1922:

"[tuve] la gran satisfacción de haber contemplado yo personalmente, así como otras muchas personas, bellísimos ejercicios de gimnasia rítmica admirablemente realizados en un instituto de gimnasia rítmica (HELLERAU en Dresden-Alemania), edificado especialmente para las enseñanzas del insigne creador de esta gimnasia, Jaques Dalcroze".49

45 A pesar de que Chávez envió una postal a su amigo Federico Mariscal, que retrataba el buque prospecto, el SS Wilhelm Kaiser der Grosse, éste viajó en su muy similar el Cecilie. Véase Archivo Histórico de la UNAM, Fondo Ezequiel A. Chávez [en adelante AHUNAM, FEACH], Asuntos personales, Correspondencia con otras personas, Caja 8, Exp. Postales, Doc. 234, 1912. El Wilhelm tuvo cierta fama, que puede consultarse en Manuel Marrero Álvarez, "Vapor 'Kaiser Wilhelm der Grosse'. Esplendor de los mares en la paz, temible corsario en la guerra": La Prensa (7 de enero de 2017), pp. 1-3.

46 Manifest. Department of Commerce and Labor. Immigration Service. Mexican Border District, Ancestry.mx, en línea: https://www.ancestry.mx/ [07-07-2021].

47 Véase Guerrand, “Sobre los orígenes", pp. 17-20.

48 Véase García Roig, Heinrich Tessenow, p. 88. Se debe aclarar que la fama del instituto fue precedida por intensas exploraciones empíricas de Dalcroze por lo menos desde 1905, en que ofreció una demostración de sus hallazgos y resultados, confirmados por la investigación clínica psicológica años más tarde. Spector, "Bring Back Dalcroze”, pp. 19-21. Ver también Schnebly-Black, "Reseña”, p. 161.

49 Samuel Chávez, "Lo que es la gimnasia llamada especialmente 'gimnasia rítmica' en sus relaciones con el baile y la gimnasia común": El Maestro. Revista de Cultura Nacional, 4-5 (1922), p. 469. Las citas subsecuentes de este texto se tomarán de la 
Si se imagina el azoro de Samuel ante estas novedades, no es difícil entender sus razones para involucrarse en las enseñanzas que ahí se impartieron personalmente por Dalcroze hasta 1914. La existencia entre los papeles del archivo de Chávez de un libro que al efecto publicó Dalcroze, más un ex libris de Samuel, evidenciaron su interés por la gimnasia rítmica, que fue confirmado más tarde por su amigo y colega Federico Mariscal, quien aseguraba que por lo menos desde 1917 —en realidad, fue desde 1912- aquél había mostrado una fuerte inclinación personal por el estudio del ritmo, después de degustar las actuaciones de la bailarina de padres españoles Antonia Marcé, La Argentina. ${ }^{50}$

\section{La ciudad-jardín de Hellerau: el rol fundamental del Institut Rhythmik en la vida de Samuel Chávez}

En los últimos años del siglo XIX y la primera década del XX, la Alemania guillermina (por el káiser Guillermo II) hervía de encontradas posiciones frente a la industrialización y la vida moderna. ${ }^{51}$ Muchos reformadores e intelectuales, particularmente entre la clase media o pequeña burguesía, pugnaron por encontrar una 'tercera vía' al capitalismo y al socialismo; y esa búsqueda no se constriñó a aspectos económicos, sociales, políticos o tecnológicos, sino que comprendió la cultura como un todo $y$, por supuesto, tuvo una aguda crítica a la vida urbana y el expansionismo de las ciudades, generando, en contrapartida, movimientos anti-urbanos cuyos gérmenes fueron propuestos por los socialistas utópicos. Ebenezer Howard formuló lo propio en Inglaterra, inspirando el movimiento de la ciudad-jardín, del que resultaron Letchworth (1903-1904), Welwyn (1919-1921) y numerosos sucedáneos en la forma de suburbios-jardín. ${ }^{52}$

primera edición facsimilar que imprimió el Fondo de Cultura Económica en 1979, pp. 468-483.

50 Federico Mariscal, "El arquitecto D. Samuel Chávez": Universidad. Mensual de Cultura Popular, 4: 18 (1937), p. 14.

51 Las posiciones encontradas durante esta época fueron la Kultur y la Zivilisation, donde se identificó a la Kultur con "la tradición humanista y la ciudad burguesa cuando no directamente con la vida campesina y el mundo rural- y la Zivilisation con el capitalismo moderno y la Großstadt (gran ciudad)". Sevilla Buitrago, "Großstadtkultur", p. 209.

52 Para estudiar la ciudad-jardín desde el plano conceptual e histórico, véase Ramos Gorostiza, “El descontento”, pp. 85-122. 
García Roing destaca — de entre varios - tres móviles reformistas en las ciudades: los higiénico-medicinales, los social-políticos y los religioso-filosóficos. En Alemania, de manera particular, dos movimientos son de nuestro interés a efectos de contextualizar la fundación de la ciudad de Hellerau: el de la reforma del suelo (Bodenreformbewegung) y el de la ciudad-jardín (Gartenstadtbewegung), los cuales, ambos con similitudes, buscaron, respectivamente, abogar por la propiedad colectiva del suelo y la desurbanización. En la práctica y la teoría, Hellerau fue "la sede de las modernas ideas de la Werkbund y también la realización de esas ideas", 53 ya que se logró

"el refinamiento del trabajo industrial en colaboración con el arte, la industria y los oficios a través de la educación, la propaganda y las posturas uniformes frente a cuestiones específicas". 54

No es casual que la construcción de la ciudad fuera encargada al talento de los arquitectos Richard Riemerschmid, Hermann Muthesius y Heinrich Tessenow, quienes estuvieron ligados a la Werkbund, en donde compartieron ideales con Walter Gropius, Peter Behrens, Theodor Fischer, Josef Maria Olbrich, Bruno Taut, Henry van de Velde y otros. Los arquitectos de Hellerau, en su calidad de intelectuales de los movimientos de reforma de la vida, llevaron algunos experimentos a la práctica en la forma de las Siedlungen. Al respecto, García Roig afirma:

"Uno de los aspectos que los reformadores de la vida preconizan, como fundamento de la cultura que la 'Siedlung' ha de desarrollar, se refiere a la actividad física del propio cuerpo que en contacto con la tierra, las labores agrícolas, la construcción de la casa y otras tareas relacionadas con la vida al aire libre 'colocan el cultivo del cuerpo en el punto central de toda actividad'”. 55

Es muy probable que todos estos aspectos influyeran en la decisión de fundar el Instituto de Rítmica en Hellerau, la ciudad-jardín emblemática de los movimientos de reforma de la vida.

Desde 1901 Dalcroze decantó, paulatinamente, su famoso método y para 1904 desarrolló "los primeros elementos humanos de la gimnasia

53 García Roig, Heinrich Tessenow, pp. 62 y 66.

54 Nerdinger, Deutscher Werkbund, p. 3.

55 García Roig, Heinrich Tessenow, pp. 65 y 74-75. 
sobre los ritmos de la música"; 56 por lo demás, también en Alemania realizó esfuerzos por adaptar el método a las condiciones del pueblo alemán. ${ }^{57}$ En 1909, Dalcroze recibió un telegrama de Wolf Dohrn, en el cual le pedía una demostración en Dresde, a donde acudió y conoció por primera vez Hellerau; tiempo después, en el mismo año, le escribió de nueva cuenta Dohrn para invitarlo a establecer un instituto de rítmica en la nueva ciudad-jardín. ${ }^{58}$ De hecho, es importante decir que las ideas pedagógicas de Dalcroze "postulan de manera clara la identidad del movimiento para la Siedlung con el movimiento de la cultura del cuerpo (Körperkulturbewegung)" ${ }^{59}$ y, por extensión, con el de la reforma de la educación artística, materia en la que Chávez estaba muy interesado.

Desde su concepción, Karl Schmidt y Wolf Dohrm — miembros de la Werkbund- asumieron a Hellerau como el "verdadero núcleo espiritual" de la ciudad de Dresde; 60 por ello, junto con Richard Riemerschmid, fundaron el 4 de junio de 1908 la Sociedad de la ciudadjardín de Hellerau (Gartenstadt-Gesellschaft Hellerau GmbH), en donde se situaría, cuatro años después, la Escuela para Rítmica JaquesDalcroze (Bildungsanstalt für rhytmische Gymnastik), la cual serviría a la "liberación de todas las fuerzas espirituales y creadoras por medio de la rítmica corporal". 61

Entre 1910 y 1912, mismo año, el último del congreso de Dresde al que asistió Samuel Chávez, Tessenow dirigió las obras del Instituto de Rítmica después de discutir y negociar tres proyectos con Riemerschmid. Una vez aceptado el tercer proyecto, la primera piedra fue colocada el 22 de abril de 1909 y en noviembre comenzaron las clases, pero no fue sino hasta junio de 1912 que el conjunto fue

\footnotetext{
56 Tibor D’Ênes, "Biografía de Émile Jaques-Dalcroze": Asociación Jaques Dalcroze Argentina (tr. de Juana Gargiulo), en línea: https://jaquesdalcroze.com/biografia/ [22-03-2021]. Desde 1886 Dalcroze se interesó en las manifestaciones rítmicas al presenciar las danzas de los musulmanes fanáticos Afssaouahs. Véase Teatro Popular Romando, La rítmica como entrenamiento del actor, Alicante: Biblioteca Virtual Miguel de Cervantes, 2012, p. 12, en línea: http://www.cervantesvirtual.com/nd/ark:/59851/bmcw6741 [22-03-2021].

57 García Roig, Heinrich Tessenow, p. 87.

58 D’Ênes, "Biografía”.

59 García Roig, Heinrich Tessenow, p. 75.

60 García Roig, Heinrich Tessenow, p. 83.

61 García Roig, Heinrich Tessenow, p. 84.
} 
concluido en su totalidad. ${ }^{62}$ Dados los presupuestos de los diversos movimientos de reforma de la vida, se pensó que el centro espiritual de la ciudad-jardín debió ser una suerte de Casa del Pueblo (Volkshaus), pero " no se trata ni de una escuela, ni de un museo, ni de una iglesia, ni de una filarmónica, ni de un auditórium [sic]!". ${ }^{63}$

En 1914, iniciadas las hostilidades de la Gran Guerra, Émile JaquesDalcroze abandonó Hellerau después de haber firmado una carta de protesta por el bombardeo alemán a la catedral de Reims; la escuela, no obstante, continuó parcialmente sus actividades hasta 1918, adoptando a partir de entonces el nombre de Escuela para la Educación Rítmica, Musical y Corporal (Schule für Rhythmus, Musik und Körperbildung Hellerau). ${ }^{64}$

La pasión que a Samuel le brotó por la gimnasia rítmica y, consecuentemente, por el estudio del ritmo, encajaba perfectamente con su entusiasmo y especialización por la proporción en arquitectura, que juntos, al decir de Mariscal, le condujeron al de la armonía, materia en la que "no cesó de ahondar durante el resto de sus años". $65 \mathrm{Al}$ respecto, se posee evidencia documental de su enorme interés por la proporción y la armonía, tanto en la arquitectura como en la danza y la música. El laboratorio más idóneo en el que Chávez colmó sus ansias de explorar ese campo no podía ser otro que el fundado por Dalcroze en la ciudad-jardín alemana de Hellerau. Además, Hellerau representó para Chávez la posibilidad de encontrar un punto medio entre las radicales posturas abanderadas por los movimientos revolucionarios de corte marxista y la tradición católica y elitista de su ambiente familiar.

Hellerau, pues, significó "el epítome y, el movimiento para la Siedlung, el centro de todos los movimientos que para la reforma de la vida trataron de encontrar un sendero salvífico". ${ }^{66}$ Si por un lado acogió

62 García Roig, Heinrich Tessenow, p. 88.

63 Según escribió Theodor Fischer en 1906, citado por García Roig, Heinrich Tessenow, p. 85.

64 García Roig, Heinrich Tessenow, p. 88.

65 Mariscal, "El arquitecto", p. 14. El interés de Chávez se vio acrecentado por un escrito de Vasconcelos en torno a su teoría del ritmo, publicado en 1916. Véase Vasconcelos, "Pitágoras", pp. 121-127. En el ensayo que Vasconcelos le publicó a Chávez en 1922 se encuentran pistas del empleo de la misma terminología y conceptos que a su vez usó el autor del "Ulises criollo". Chávez, "Lo que es la gimnasia", pp. 474 y 479.

66 García Roig, Heinrich Tessenow, p. 12. 
el clamor por nuevas formas de vida y de habitar, formulado por reformadores sociales que ciertamente abrigaban genuinos deseos de mejorar las condiciones de vida de la clase obrera, por otro, temieron la consigna de la lucha de clases y pugnaron, en cambio, por una solución cuya implementación, en la práctica, los alejaba del colectivo proletario en favor de una visión pequeñoburguesa (o de clase media) muy proclive a una retórica que conjugó antibelicismo, (supra)nacionalismo y renovación espiritual. Quizá fue esto último lo que llamó la atención de Chávez: de familia perteneciente a la elite porfiriana, con los tiempos que corrían al doblar el crucial año de 1910, tendría que adaptarse a las nuevas condiciones de México y el mundo, pero sin declinar un ápice de sus certezas religiosas.

Por convicción o necesidad de adaptación, Samuel Chávez comenzaba a trastocar el mullido y discreto encanto de la elite porfiriana en la que nació, creció y se preparó profesionalmente. Si sus convicciones religiosas no sufrieron cambio alguno, su formación Beaux-Arts tuvo por necesidad que ser revisada ante la extraordinaria influencia de los artistas e intelectuales que con afán buscaban la reforma no sólo de las artes, sino, como se ha visto, de la vida entera, incluyendo la vida en las ciudades. Cabe decir que el concepto de reforma estuvo ligado a una "forma de habitar" en que "la educación [constituyó un] punto esencial de una renovación cultural más amplia"; es decir, aquel tipo de formación que convirtió a Hellerau en una auténtica "provincia pedagógica". ${ }^{67}$

Justo en este contexto nació la experiencia del Instituto de Rítmica, en medio de una Alemania que mantenía un productivo cuanto riesgoso esquema de crecimiento económico e industrial. El fatalismo histórico al que condujo el pathos guillermino, consistente en el crecimiento económico ilimitado, fue, hasta cierto punto, revertido por

"las condiciones implícitas en el trabajo artesanal y en la pequeña ciudad [ya que hicieron] posible un nuevo florecimiento, un nuevo renacer del hombre". 68

Ahí yacía el nuevo programa de la ciudad-jardín de Hellerau y su extraordinaria aura para atraer, cual abejas a un panal, a una pléyade de artistas, intelectuales y reformadores de Europa central y del mundo. Sin embargo, esta reacción palideció con la primera conflagración

67 García Roig, Heinrich Tessenow, p. 17.

68 García Roig, Heinrich Tessenow, p. 22. 
mundial (1914-1918). La guerra constituyó la "salida normal de un tiempo dominado por la técnica" $69 \mathrm{y}$, por consiguiente, el predominio de los medios sobre los fines encontró

"su expresión más acendrada en el hecho de que las cosas que se encuentran fuera de la espiritualidad de la vida, en su periferia, se han apoderado del centro de la misma, y por lo tanto de nosotros mismos". ${ }^{70}$

Samuel Chávez, con base en su experiencia personal, así como en la de su hermano Ezequiel y la de José Vasconcelos, concordó con estos llamados a la espiritualidad, presentes en los escritos de Tessenow (autor del proyecto y director de obra del edificio del Instituto Hellerau). ${ }^{71}$ Se puede afirmar que el mismo tipo de profundas motivaciones les fue común a Samuel y su hermano Ezequiel, por lo que toca al valor de la sensibilidad, de lo emocional, como búsqueda y camino a lo espiritual.

$\mathrm{Al}$ respecto, en Tessenow se advierte que

"Frente a los intereses particulares, que suponen deformaciones de lo que se considera el estado original del hombre, lo humano, espiritualizar (vergeistigen) supone ponderar lo sentimental frente a lo racional, acentuar en nuestra vida el valor de los lazos interiores (die inneren Verbindungen) que nos unen al mundo frente a nuestras relaciones externas puramente superficiales". ${ }^{72}$

No obstante, como se explicó, estos planteamientos fueron expresión más bien de sectores de intelectuales que de la clase obrera. Así, para el final de la guerra en 1918,

"la preocupación por la vida del espíritu, como contrapeso opuesto a la técnica, informa [...] el pensamiento de los grupos e intelectuales más activos. Se trata, en general, de un socialismo ético, en determinados casos situado por encima del pueblo y de raigambre exclusivamente intelectual (que postula, por ejemplo, una educación de la nación hacia el espíritu, una revolución cultural frente a teorías de la cultura proletaria como la lucha de clases)".73

De manera particular, para el caso de México, este programa ideológico alemán también animó las preocupaciones de distintos intelectuales de

${ }^{69}$ García Roig, Heinrich Tessenow, p. 22.

70 García Roig, Heinrich Tessenow, p. 22.

${ }^{71}$ El proyecto definitivo, "tercero de una serie de variantes", se aprobó en 1911. Quesada, La caja, p. 155.

72 García Roig, Heinrich Tessenow, p. 23.

73 García Roig, Heinrich Tessenow, pp. 23 y 27. 
la época, como Vasconcelos y Ezequiel A. Chávez, siempre y cuando se despojara de cualquier referencia socialista, así fuera ética.

En un estudio previo que se realizó sobre Samuel Chávez y el Plano de las Colonias, ese ambiente cargado de anhelo espiritual y de trascendencia - que se registra en Europa en el período 1896-1906conformó un extraordinario caldo de cultivo para toda clase de experiencias artísticas y de intervenciones a nivel arquitectónico y urbano, como la pedagogía espacial de lo corporal que Chávez plasmó en aquella propuesta urbanística. Al atestiguar lo que se enseñaba en el Instituto Hellerau, al vivir sus espacios interiores y contemplar su fachada, sería inverosímil que no estuviera al corriente de lo que tanto Dalcroze y Appia como A. von Salzmann y Tessenow representaban para esta institución. ¿Esto influyó en las convicciones de Samuel Chávez? No resulta del todo desproporcionado pensar que sí.

La contemplación y, sobre todo, la vivencia del gran vestíbulo de ejercicios del Instituto Hellerau, producto de la colaboración entre Tessenow, Appia, Dalcroze y Salzmann, ${ }^{74}$ que era una enorme caja vacía de 50 metros de largo, 16 de anchura y 12 de alto, debieron dejar pasmado a Samuel, al punto de hacer entrar en crisis o al menos remover todo su sistema de certezas arreglado a la tradición BeauxArts, y que precisamente en el Instituto Hellerau se vio aniquilado en favor de nuevas posturas teórico-prácticas que respondían en todos los niveles "a la idea de Appia del espacio ilimitado"; es decir, en el que se efectuaría una nueva relación entre la música, la danza y la arquitectura. ${ }^{75}$

Ahí pudo haber experimentado Samuel Chávez, de primera mano, la estrecha relación entre la música, el ritmo y la arquitectura, esto es, entre el tiempo, el movimiento y el espacio, pues Appia llevó a cabo sus teorías de un "teatro verdaderamente revolucionario", en donde escena y espacio conformaban una "unidad espacial" para los espectadores: esta unidad sólo estaría completa "con la presencia del cuerpo en

\footnotetext{
${ }^{74}$ Asegura Gálvez Pérez que fue en el Hotel Terminus de Lausanne, en el verano de 1911, “donde se produjo el encuentro entre A. Appia, J. Dalcroze, H. Tessenow y A. von Salzmann para tratar temas referentes a las obras de la sala de representaciones en Hellerau". Véase Gálvez Pérez, Materia, p. 28.

${ }^{75}$ Quesada, La caja, p. 157.
} 
movimiento, a través del ritmo", y, por ende, la "acción activaría todo el espacio". 76

García Roig sostiene que las dimensiones del espacio principal, en ancho y largo, establecieron una proporción 1:2, por lo tanto, se trató de un doble cuadrado (tridimensionalmente dos cubos espaciales), cuya razón se correspondería con el intervalo musical del diapasón; y dicho doble cuadrado se verifica muy aproximadamente entre el ancho de la sala de representaciones (16 $\mathrm{m}$ a paños interiores) y su largo hasta el décimo primer intercolumnio o la décima segunda columna de dicha sala, contada desde el frente hasta el fondo (34 $\mathrm{m}$ a paños interiores); dicho de otra manera, la sala fue sólo 2 metros más larga del doble exacto: la formación de los dos cubos espaciales indicados es prácticamente un efecto visual. La proporción de la altura y el ancho correspondió, en cambio, al intervalo musical denominado diatésaron: 3:4 $(12 \mathrm{~m} / 16 \mathrm{~m}) \cdot{ }^{77}$ Todo el plan del edificio que contiene a la sala, estuvo resuelto aproximadamente en un cuadrado 'achatado', subdividido en nueve cuadros menores, a la manera de la "carta del patrón de nueve situaciones" del sistema de François Delsarte, ${ }^{78}$ que como se sabe, fue un antecedente y una influencia crucial en la rítmica de Dalcroze (ver Figura 1).

76 Gálvez Pérez, Materia, p. 29.

77 García Roig, Heinrich Tessenow, p. 93.

78 Gálvez Pérez, Materia, p. 22. 

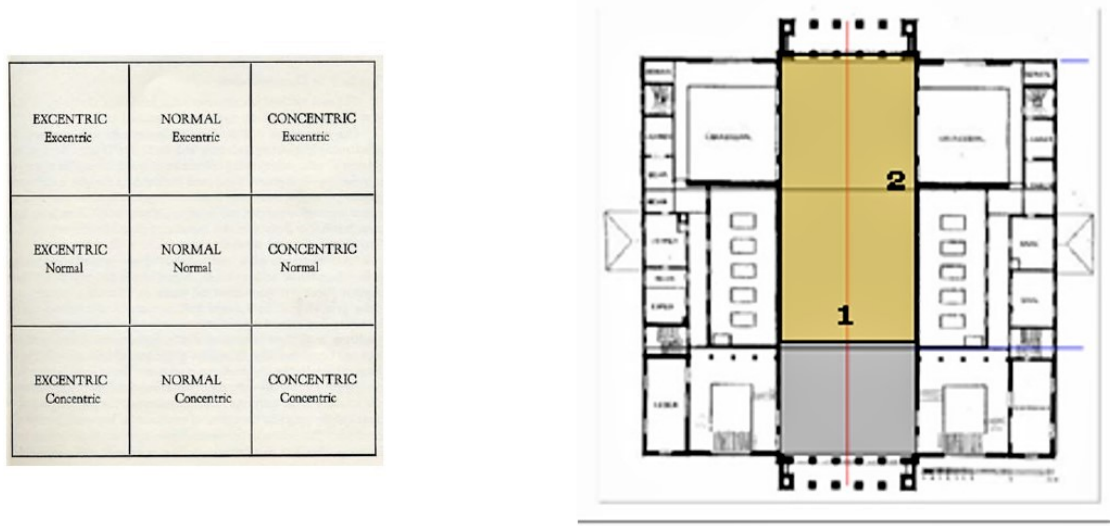

Figura 1: Izquierda: Patrón de Nueve Posiciones de Delsarte; derecha: planta del Instituto Dalcroze, con el patrón sobrepuesto. Cortesía de los autores con base, respectivamente, en Gálvez Pérez, María Auxiliadora, p. 22 y Ruiz Ortiz, Susana, "Hellerau Festspielhaus", en línea: https://slideplayer.es/slide/5460675 [2503-2021].

Para Dalcroze, el "único lugar donde poesía, música y espacio podían reunirse era el cuerpo vivo". ${ }^{79}$ En Hellerau, Tessenow supo entender muy bien esta búsqueda, al grado de proponer su caja vacía para la gran sala del Instituto de Rítmica, carente de arco que enmarcara un proscenio inexistente, sin isóptica (aunque eventualmente pudiera montarse una gradería con esta condición) y con un foso de orquesta "que podía cubrirse por completo dejando un único plano de suelo a nivel"; 80 es decir, un esquema funcional completamente subordinado a la práctica de la gimnasia rítmica, que mereció elogios de CharlesEdouard Jeanneret (después llamado Le Corbusier), ${ }^{81}$ quien visitó dos veces el instituto entre 1910 y 1913 —en donde, por cierto, trabajaba su hermano Albert como músico residente. ${ }^{82}$

79 Jacques Rancière, Escenas del régimen estético del arte, Buenos Aires: Ediciones Manantial, 2013, p. 217.

80 Quesada, La caja, p. 157.

81 Quien llegó a decir que "Hellerau marcará un punto capital en la evolución artística de la época”; ver su Carnet III en Alejandro Vírseda Aizpún, Le Corbusier y el proyecto para Sainte Marie de la Tourette. De la celda al espacio inefable, España: Universidad Politécnica de Madrid, 2014 (vol. 2) (tesis doctoral), p. 318.

82 García Roig, Heinrich Tessenow, p. 94. 


\section{El potencial pedagógico de la gimnasia rítmica}

La formación de la ENBA, basada en la tradición de la École des BeauxArts, proporcionó a Samuel Chávez un entrenamiento riguroso en el manejo y dominio de la proporción, el ritmo y la armonía, como lo demuestran sus distintos proyectos arquitectónicos y su pasión personal por esas materias. Por consecuencia, se puede sospechar que aquella tradición lo mantuvo hasta cierto punto maniatado, ya que dependía mucho de la razón matemática y, por ende, de la abstracción; es decir, era más cerebral que emocional. Sin embargo, de manera paulatina se fue incorporando al movimiento de renovación arquitectónica gracias al empleo, como ya se dijo, de algunas innovaciones; como ejemplo,

"Samuel Chávez había alcanzado $17 \mathrm{~m}$ de espacio libre entre apoyos en el anfiteatro Simón Bolívar, inserto en todo el conjunto de estructura realizada con el sistema Hennebique [el hormigón armado] para la Escuela Nacional Preparatoria". 83

83 Mónica Silva Contreras, "Arquitectura y materiales modernos. Funciones y técnicas internacionales en la ciudad de México, 1900-1910": Boletín de Monumentos Históricos, 3: 22 (2011), p. 204. 


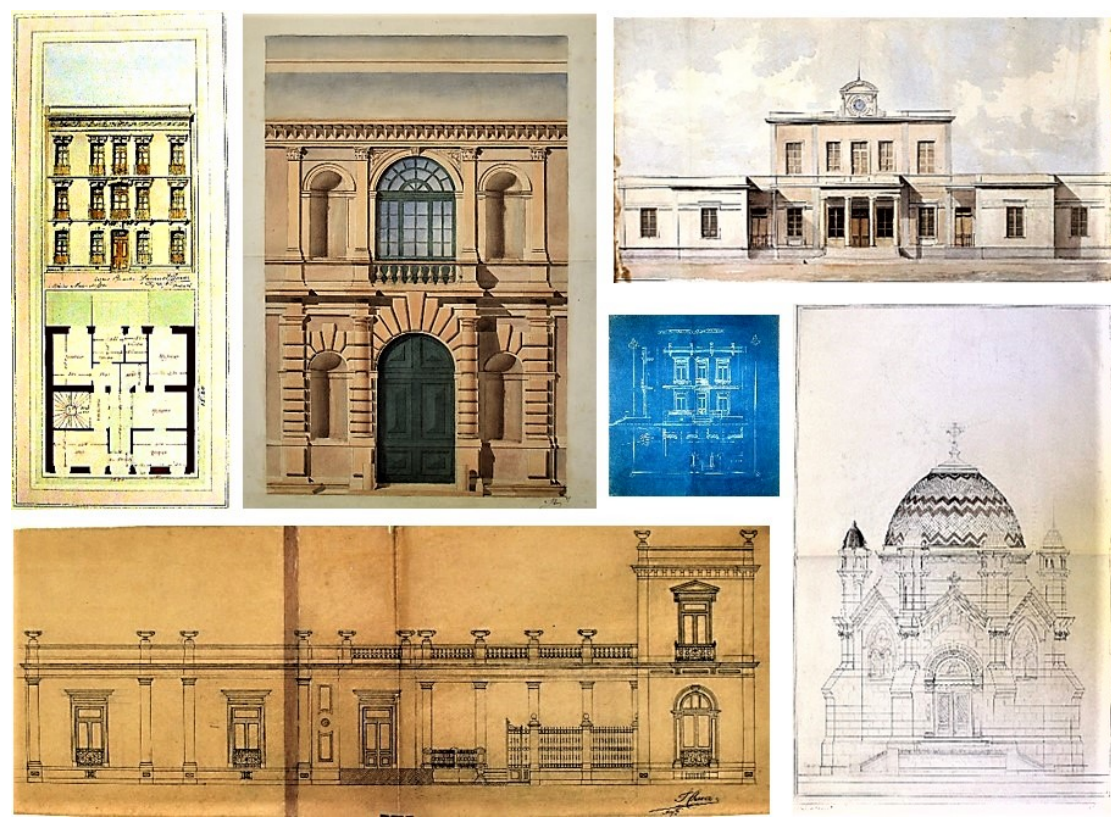

Figura 2: Dibujos y proyectos de Samuel Chávez, en los que destaca el manejo rítmico y proporcionado del todo y las partes. Cortesía del APSChL, en proceso de catalogación.

Así pues, tanto en Samuel como en su hermano Ezequiel hervían una sensibilidad y una espiritualidad que encontraron un canal de desfogue en su acendrada religiosidad y sus manifestaciones visibles: respecto al primero, en su pedagogía espacial de lo corporal, ${ }^{84}$ inscrita en su Plano de las Colonias de la ciudad de Aguascalientes, y en su progresivo interés por la danza y la música; mientras que en el segundo, en sus reflexiones filosóficas, que tomaron forma en libros y conferencias.

Si el problema de armonía ocupó las mentes de destacados personajes de la filosofía, las letras y las artes desde el siglo XVIII hasta principios del XX, el del ritmo comenzó a excitar las inquietudes de teóricos y ejecutantes de las artes escénicas desde mediados del siglo XIX. Artaud, Meyerhold, Piscator, Brecht, Stanislavski, Craig, Barba, Grotowski, Delsarte, Appia y, por supuesto, Dalcroze reflexionaron y experimentaron nuevas formas del arte escénico, con contradicciones, desacuerdos, énfasis, intereses distintos y matices más o menos

84 Sifuentes, “Una pedagogía”, pp. 21-32. 
evidentes. Entre los extremos de Artaud y Dalcroze existió un punto en común: "la primacía de lo sensible", de modo que "lo que la doctrina de Dalcroze pretende es 'reemplazar una enseñanza cerebral por un despertar sensible'". 85 De tal manera, Dalcroze apuntó que el objetivo principal de su gimnasia era:

“crear a través de la rítmica una corriente rápida y regular de comunicación entre el cerebro y el cuerpo; [por lo que] mis ejercicios físicos [...] está[n] concebido[s] de tal forma que puede[n] establecer más rápidamente en el cerebro la imagen del movimiento estudiado". 86

Queda claro que Dalcroze lo que buscó fue hacer de la música un símbolo visible a través de la expresión corporal. A tal efecto, inventó ejercicios destinados a

"reconocer la intensidad de los sonidos, a medir los intervalos, a escrutar los sonidos armónicos, a individualizar las diversas notas de los acordes, a seguir los dibujos de los contrapuntos de las polifonías, a diferenciar las distintas tonalidades, a analizar las relaciones existentes entre las sensaciones auditivas y las sensaciones vocales, a desarrollar la calidad receptiva del oído". 87

Nunca estuvo en la mente de Dalcroze equiparar la rítmica con una escuela de danza, sino que la consideró como la base de todas las artes. Fue, con todo, una experiencia personal, imposible de comprenderla sin haberla vivido. Pero como dicha experiencia elevaba el alma por encima de la materia, ${ }^{88}$ su carácter personal y experiencial debieron constituir una fuerte motivación para que Samuel se decantara por esta práctica, que surgía de todo punto tan acorde a las exploraciones filosóficas de su hermano Ezequiel sobre la primacía de lo trascendente por sobre lo inmanente, y de las del ideólogo Vasconcelos respecto a la fluencia corporal hacia lo Absoluto y lo Infinito.

Los ejercicios que creó Dalcroze hacían que se reforzara "el sentimiento métrico y el instinto de ritmo", sin llegar a confundirlos, pues la métrica era de origen intelectual, mientras que la rítmica era producto del instinto; una surgía de la reflexión, la otra de la intuición. ${ }^{89}$ Pero aún más, Dalcroze escribió en 1919 que la educación del mañana

85 Teatro Popular Romando, La rítmica, p. 8.

86 Jaques-Dalcroze, The Eurhythmics, p. 19.

87 Teatro Popular Romando, La rítmica, p. 13.

88 Teatro Popular Romando, La rítmica, p. 13

89 Teatro Popular Romando, La rítmica, p. 15. 
debía contemplar la reconstrucción, preparación y adaptación del ser humano para la provisión de la máxima fuerza con el mínimo de desgaste y de resistencia. Es decir, en palabras de Quesada, la ritmificación

"consistía en trazar un puente entre la conciencia táctil-motriz y la conciencia espacial, y el objetivo es el de la acción concreta, el máximo de resultados productivos, aunque no necesariamente materiales, con el mínimo esfuerzo energético y nervioso". .90

De tal modo, "Dalcroze distingue en el cuerpo varios componentes con respecto a la música: el oído y la voz conforman la conciencia del sonido, mientras que el cuerpo entero conforma la conciencia del ritmo". ${ }^{91}$ De hecho, en la filosofía griega también orbitaron estas ideas: para Platón la armonía y el ritmo son lo que "más penetra en el interior del Alma y la afecta más vigorosamente, trayendo consigo la Gracia". ${ }^{92}$ La práctica de la gimnasia rítmica sólo podría reportarle a Samuel Chávez beneficios a su cuerpo y su alma, ${ }^{93}$ cuanto y más si, como su hermano, buscaba con ansia la intuición de lo Infinito.

Aún no se tiene la seguridad de que Samuel Chávez se haya quedado en el instituto tras el congreso de Dresde, luego de presenciar personalmente la demostración del jueves 15 de agosto, aunque ya

90 Quesada, La caja, pp. 153.

91 Quesada, La caja, pp. 151-153.

92 Gastón Clerc González, La arquitectura es música congelada, España: Escuela Superior de Arquitectura de Madrid, 2003 (tesis doctoral), p. 124.

93 Samuel y Ezequiel, ambos aquejados por afecciones respiratorias, conocieron la gimnasia pedagógica desde la niñez, ya que ésta estaba incluida en el programa de todas las escuelas de Aguascalientes (Chávez González, "La introducción”, pp. 7879). Años después, escribió Miguel Macedo, profesor en la Escuela Preparatoria Nacional, que Ezequiel "ha leído ya varios tratados sobre gimnasia sueca", seguramente por recomendación de su papá (Chávez, Recordando, p. 88). Esta gimnasia se privilegió en la familia Chávez Lavista respecto a otras, como la alemana, porque "los ejercicios respiratorios ocupan [...] un lugar importante" (Kumlien / André, La gimnasia, p. 17). Durante el gobierno de Porfirio Díaz y la influencia pedagógica de Ezequiel A. Chávez, en las escuelas normales mexicanas se fomentó un tipo de gimnasia llamada "racional", junto con el "solfeo modal". Véanse Alicia Tecuanhuey / María del Carmen Aguirre (eds.), Escuela laica, escuela socialista. La educación en México, 1881-1940, México: Asesoría y Tecnologías en Gestión Educativa, 2016, p. 42; y Chávez González, "La introducción", p. 78. 
posterior a ese evento sí se tiene la certeza de que permaneció en Europa hasta febrero de 1913, en que regresó a Nueva York en el mismo trasatlántico, el Cecilie. ${ }^{94}$

\section{Samuel Chávez y su vocación pedagógica en rítmica}

En los años inmediatos al inicio de las hostilidades de 1910, la antigua Academia de San Carlos y su sucedánea, la ENBA, presentaba un sistema educativo completamente "atrofiado", con una enseñanza "estática y encallada en la rutina",95 desfasada totalmente de los impulsos renovadores y reformistas que en Europa se estaban desarrollando a extramuros de las Academias de Bellas Artes.

En semejante sistema anquilosado fue constate y abundante la práctica del dibujo en blanco y negro, la ejecución de naturalezas muertas, modelos desnudos y vestidos, copias del yeso, pintura al óleo, composición; y, en arquitectura, estilos de ornamentación en los edificios, una materia muy apreciada por Samuel Chávez y, como se mencionó en apartados anteriores, de la que fue titular en la ENBA.

A sólo un año antes de que Samuel partiera como delegado del gobierno mexicano al congreso de Dresde, la crispación en la ENBA alcanzó tal magnitud, a mediados de 1911 (para ser precisos el 28 de julio), que se produjo una "huelga",96 la cual terminó con la separación

94 El Cecilie llegó a Nueva York el 26 de febrero de 1913, contando entre sus pasajeros a Samuel, su esposa Rosenda y su hija Rosita. Ver The Statue of LibertyEllis Island Foundation, Búsqueda de pasajeros, en línea: https://www.libertyellisfoundation.org/passenger [22-03-2021].

95 Povedano Marrugat, Arte, p. 375.

96 Que según Povedano tuvo lugar el 29 de junio, véase Povedano Marrugat, Arte, p. 374. Pilar García aduce que no se trató de una huelga propiamente dicha, sino de un conflicto interno entre estudiantes y autoridades, véase Pilar García, "Hitos canónicos. La huelga de 1911 en la Escuela Nacional de Bellas Artes": Esther Acevedo (ed.), Hacia otra historia del arte en México. La fabricación del arte nacional a debate (1920-1950), México: CONACULTA, (vol. 3), 2002, pp. 105-125. Xavier Moyssén asegura que la huelga fue el 28 de julio y que sólo se prolongó hasta 1912, véase Xavier Moyssén, "Siqueiros antes de Siqueiros": Anales del Instituto de Investigaciones Estéticas, 13: 45 (1976), p. 179; Jorge Morales es de la misma opinión, señalando el mes de abril de 1912 como fecha límite del paro, véase Jorge Morales, "Notas para una historia crítica de 'La Esmeralda'. La cuestión de sus orígenes (1927, 1943)”: Discurso Visual, 3: 36 (2015), pp. 12 y 14. 
de su director, el arquitecto Antonio Rivas Mercado. ${ }^{97}$ Este conflicto se prolongó hasta el año 1912, según unas fuentes; o hasta 1913, según Povedano, siendo instalado entonces en la dirección de la escuela "el candidato de los estudiantes" inconformes, el pintor Alfredo Ramos Martínez, cuyo sucesor, Gerardo Murillo, el Dr. Átl, ${ }^{98}$ promovió la renovación pedagógica que le urgía a la institución y que acaloradamente demandaban los estudiantes. Dichos impulsos renovadores se produjeron en el curso del predominio de la influencia pedagógica de Ezequiel A. Chávez, soportada en los diversos cargos que ocupó en la administración pública y la Universidad Nacional.

Diversas vicisitudes más tuvieron lugar en los años posteriores. En ese ínterin, entre 1912 y 1920, los sistemas educativos fueron escalando desde solicitaciones políticas debidas al proceso de construcción del país tras la revolución armada, hasta las reformas pedagógicas tanto en la enseñanza básica como en la especializada de las artes y los oficios, colocando así al país en una posición más acorde a los avances que en la misma dirección se habían experimentado en Europa desde finales del siglo XIX. De acuerdo con Tecuanhuey y Aguirre, el "tiempo en que se privilegiaban los temas pedagógicos dentro de la temática educativa había terminado y junto con eso terminaba la influencia de Ezequiel A. Chávez". La educación avanzaba "hacia su centralización y control por el Estado". 99

En México, la llegada al poder de Álvaro Obregón significó el comienzo de un nuevo fenómeno reformador en todo el ámbito educativo, que interesaba particularmente el artístico. En efecto, Povedano señala que:

"Poco a poco se fueron descubriendo los beneficios de la educación artística: se creyó conveniente la constitución de una Dirección de Cultura Estética y el fomento de la educación del pueblo mediante diversos espectáculos. Estamos

${ }^{97}$ José Antonio Rivas Mercado fue admitido en 1872 a la École des Beaux-Arts de París, siendo uno de los pocos arquitectos latinoamericanos educados en dicha escuela durante el siglo XIX. Véase Luis Manuel Jiménez Madera, "Arquitectos latinoamericanos en la École des Beaux-Arts de París en el siglo XIX": Revista de Arquitectura, 17: 1 (2015), p. 84.

98 Povedano Marrugat, Arte, p. 375. Dr. Átl fue el pseudónimo del pintor y escritor mexicano Gerardo Murillo Cornado.

99 Tecuanhuey / Aguirre, Escuela, p. 45. 
ante la era de José Vasconcelos como secretario de Educación durante el periodo presidencial de Álvaro Obregón". 100

Pero, como se dijo, la influencia de Ezequiel A. Chávez ya había menguado ante el empuje y apoyo gubernamental a la nueva generación de jóvenes que surgieron al calor y cobijo de la revolución triunfante. En este apretado contexto surgieron algunas revistas culturales de enorme trascendencia. Entre ellas, la nombrada con el sugestivo título de El Maestro, auspiciada por la Universidad Nacional y después por la recién creada Secretaría de Educación Pública. ${ }^{101}$

En el número correspondiente a enero-febrero de 1922, apareció un extenso texto de Samuel Chávez, titulado "Lo que es la gimnasia llamada especialmente 'gimnasia rítmica' en sus relaciones con el baile y la gimnasia común”. 102

En este texto, se aprecia que tanto para Chávez como para su maestro Jaques-Dalcroze, la gimnasia rítmica fue, ante todo, una expresión producto de una representación mental de movimientos rítmicos que se elaboraba simultáneamente a su ejecución; es decir, no fue una representación disociada de la acción misma o una deliberación a priori cuya consecuencia fuera la actividad, como ocurría con el diseño en la arquitectura. Representación y acción fueron una y la misma cosa. La gimnasia rítmica le obligó a pensar y actuar conciliando y coordinando los problemas de extensión (el espacio), la duración (el tiempo) y la energía (el movimiento).

La revelación que le acarreó su "descubrimiento" de la "música de la plástica" le produjo una viva impresión, palpable en su confesión de haber encontrado una "íntima relación" entre esta gimnasia estética y sus "tendencias vocacionales" por la arquitectura y las artes plásticas. Y

100 Povedano Marrugat, Arte, p. 383. Véase también José Iturriaga, "La creación de la Secretaría de Educación Pública”: Fernando Solana / Raúl Cardiel / Raúl Bolaños (eds.), Historia de la educación pública en México (1876-1976), México: Fondo de Cultura Económica, pp. 157-165.

101 La revista El Maestro fue "el corolario ideal a la labor planeada por Vasconcelos", Mario Aguirre / Valentina Cantón, Revista El Maestro (1921-1923). Raíces y vuelos de la propuesta educativa vasconcelista, México: Universidad Pedagógica Nacional, pp. 51-53.

102 El último apartado del artículo estaba expresamente elaborado con base en el libro de Dalcroze sobre su método de rítmica, del que Samuel poseía un ejemplar. Dicho libro de Dalcroze se encuentra en APSChL, en proceso de catalogación. 
lo que es más, atisbó el potencial pedagógico para educar el cuerpo conforme sus capacidades físicas y mentales, pues para él la gimnasia rítmica significaba la adquisición de hábitos de desarrollo de coordinación "de actividades mentales, del sentimiento y de la voluntad". El ritmo

"se encuentra en todo lo que existe en la naturaleza y se manifiesta con una variedad infinita de formas. El ritmo, en general, es una armonía o correlación de partes y una composición de arte se manifiesta por una repetición regular de rasgos semejantes". 103

Al retomar la etimología griega para la palabra ritmo, entendida como "movimiento arreglado y medido",104 Chávez enfatizó dos aspectos cruciales tras el significado del término: el de las disposiciones simétricas (o armónicas) y el de la coordinación de agrupaciones, es decir, "disposiciones de partes semejantes dispuestas de un modo semejante en un conjunto"; por ello, el ritmo, "o sea esa proporción rítmica", "se manifiesta en los movimientos de todo cuanto nos rodea" e, inclusive, en nosotros mismos. ${ }^{105}$

La gimnasia rítmica tenía por base un hecho fundamental:

"Cuando al mismo tiempo que se hace un ejercicio, o sea una experiencia física de movimientos corporales, se representa uno mentalmente esos movimientos y se tiene así una percepción clara de la sucesión y duración de las formas de los movimientos que se ejecutan en relación simultánea con su ejecución, se experimenta lo que se llama el sentido rítmico"106

lo que ocurre cuando "simultáneamente",107 al ejecutar los ejercicios gimnásticos

"uno se los representa en sus relaciones temporales, o sea de tiempos de duración de los diversos movimientos elementales que forman el conjunto y en las relaciones especiales o plásticas, o sea relaciones de forma de esos movimientos". 108

103 Chávez, "Lo que es la gimnasia”, pp. 468-469.

104 Chávez, "Lo que es la gimnasia”, pp. 470.

105 Chávez, “Lo que es la gimnasia”, pp. 469-470.

106 Chávez, "Lo que es la gimnasia", pp. 470-471

107 Chávez, "Lo que es la gimnasia”, pp. 470-471

108 Chávez, "Lo que es la gimnasia”, pp. 470-471. Las negritas son nuestras. 
Samuel recalcó así su convicción de que la gimnasia rítmica era "una gimnasia de coordinación de las sensaciones de los movimientos que se ejecutan con la percepción del ritmo de esos movimientos".109

Cabe la inquietud de si efectivamente Samuel Chávez se estaría rebelando contra las enseñanzas del sistema Beaux-Arts que constituyó toda su formación en la ENBA, en donde se fomentaba el aprendizaje del dibujo por copiado e imitación. Este procedimiento podría haber sido funcional para la pedagogía decimonónica, que postulaba la enseñanza objetiva (esto es, positivista) de tradición estadounidense, pero no para las tendencias pedagógicas que surgieron en Europa en las primeras décadas del siglo XX. En todo caso, su formación en la ENBA sí que lo había preparado, como se ha indicado repetidamente, en el conocimiento y aplicación de las proporciones y la armonía arquitectónicas, en las que la noción de ritmo era fundamental.

La correspondencia o concordia entre las potencias interiores y exteriores del ser humano conducía a realizar un ritmo mental, "resultante de ese ajuste continuo, disposición simétrica, ordenamiento o coordinación" 110 y, por tanto, alcanzar la comprensión y el placer eurítmico, determinado por los ritmos hermosos. En tal tenor, Chávez agregaba que: "El mayor adelanto y satisfacción de un ser consciente, está determinado por el mayor desarrollo en él de ritmos armónicos, con los ritmos fundamentales del desarrollo universal". ${ }^{111}$ Con otras palabras, mutatis mutandi, esta declaración suena muy semejante a la prédica filosófico-religiosa de su hermano Ezequiel, quien aspiraba a poner su alma en consonancia con la intuición de lo Infinito; para Samuel, al estar los ritmos mentales y corporales relacionados con los ritmos generales de la naturaleza, la práctica de la gimnasia rítmica "hace comprender el ritmo universal",112 expresión que, también, resuena como un eco de la doctrina vasconceliana del ritmo. Lo que pretendía Samuel Chávez, pues, era establecer las bases para la enseñanza de la gimnasia rítmica - en su sentido artístico- en las escuelas como parte de la educación, y ya no como simple instrucción de los niños, aspecto que veía con buenos ojos el secretario de Educación Pública, José Vasconcelos.

109 Chávez, "Lo que es la gimnasia", pp. 470-471.

110 Chávez, "Lo que es la gimnasia", p. 473.

111 Chávez, "Lo que es la gimnasia”, p. 473.

112 Chávez, "Lo que es la gimnasia", p. 474. 
Entre los papeles del archivo particular de Samuel Chávez se encontró una suerte de borrador de síncopas, 113 a manera de diagrama de movimientos corporales de niños en edad escolar. Más allá de que no está firmado ni fechado, el diagrama es bastante ilustrativo de las tesis sostenidas por Dalcroze y Chávez. Considérese lo que señala nuestro personaje:

"para definir una formación rítmica que interpreta sonidos por medio de movimientos, no habría inconveniente en considerar todos los sonidos iguales entre sí, o sea de igual altura, pues los elementos del ritmo formado con movimientos, sólo interpretan las duraciones y las acentuaciones", 114

y eso bastaría para tener "una muy clara PERCEPCIÓN DE RITMOS DE TIEMPOS Y ACENTUACIONES [sic], que son fundamentales en las composiciones musicales". ${ }^{115} \mathrm{Y}$ en el diagrama las figuras musicales (redondas, blancas, negras, con puntillo) aparecen precisamente con la misma altura (misma tonalidad) (Figura 3).

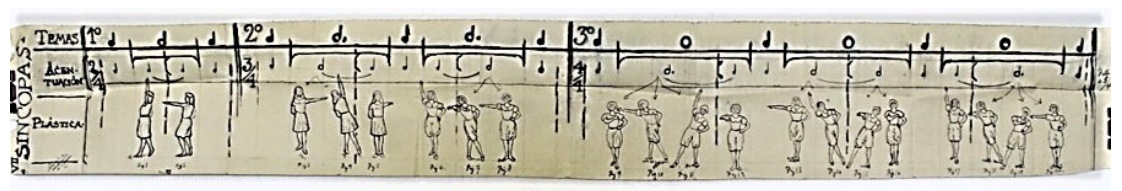

Figura 3: Diagrama de movimientos de gimnasia rítmica. Cortesía del APSChL, en proceso de catalogación.

Chávez, incluso, fue más allá de eso, pues aclaraba que la percepción de la estructura rítmica de las composiciones podría resultar una complicación para los niños, de suerte que si, en cambio,

"para interpretar la escritura musical con movimientos, solamente se consideran las duraciones que expresan las formas de las notas, esto lo harán fácilmente aun los niños pequeños, guiados por un hábil profesor".116

Y agregaba:

“Son muy interesantes como práctica para la apreciación rápida de valores relativos de las notas y como estudio de interpretaciones de notas ligadas entre

113 Se supone eso por el hecho de que está dibujado a mano, como si fuese un apunte preparatorio para su posterior presentación en limpio.

114 Chávez, "Lo que es la gimnasia", p. 476.

115 Chávez, "Lo que es la gimnasia”, p. 476.

116 Chávez, "Lo que es la gimnasia”, p. 478. 
sí, formando una nota de mayor duración, los ejercicios con movimientos relacionados a combinaciones rítmicas formadas con notas ligadas de distintos valores (redondas, blancas con puntillo, blancas, negras o corcheas): primero, realizando, según el caso, cuatro movimientos o cuatro conjuntos de movimientos, equivalentes cada movimiento o conjunto de movimientos a una negra, para interpretar una nota redonda; tres movimientos o conjuntos rápidos, para interpretar una blanca con puntillo, dos para interpretar una blanca; una para interpretar una negra, y uno más rápido para interpretar una corchea, cuidando, en todo caso, de marcar oportunamente con los movimientos la acentuación que se indique en la escritura. Segundo, haciendo estos movimientos anteriores con una parte del cuerpo, por ejemplo con los pies, y simultáneamente con otra parte del cuerpo o con enunciaciones, marcando cada conjunto de notas de la combinación rítmica que, representada como una unidad, se trata de interpretar con un solo movimiento o una enunciación." 117

La contrastación del texto con el diagrama deja pocas dudas de su autoría, por lo que ya no es necesario ahondar más en esto. Lo que sí se ha de recalcar es el siguiente pasaje, que fue fundamental no sólo para entender dónde encajaba uno de sus inventos relacionados con la música, sino también para confirmar nuestras hipótesis. En dicho pasaje, Samuel Chávez refrendaba las definiciones y distinciones, respectivamente, de la música y la gimnasia en general, con la gimnasia rítmica en particular, considerando que ésta buscaba

"producir un desarrollo rítmico de nuestro organismo y de nuestra mentalidad, capacitándonos para percibir e interpretar inteligentemente los ritmos del movimiento y darnos cuenta del ritmo universal". 118

De esta manera, se transcribe el último pasaje del apartado antes dicho:

"Cuando se ha aprendido a interpretar con movimientos el ritmo de los tiempos de duración de las notas de una composición musical, se podrá producir fácilmente el ritmo, con las propias entonaciones de las notas de la escritura, tocándolo en un instrumento 'pneumaphono,' o en un instrumento musical cualquiera, provisto de un ajuste 'pneumaphono' y esto se podrá hacer aun no teniendo conocimientos previos relativos a la altura de los sonidos de la escala musical." 119

Es decir, que su tímpano pneumáfono (o pneumaphone bells, según la patente en inglés) fue desarrollado en directa conexión con sus

117 Chávez, "Lo que es la gimnasia", p. 478.

118 Chávez, "Lo que es la gimnasia”, pp. 478-479. Las negritas son nuestras.

119 Chávez, "Lo que es la gimnasia”, p. 479. 
exploraciones dancísticas, mediante el estudio y la práctica de la gimnasia rítmica. Y ésta, a su vez, en concordancia con las nociones y conceptos de ritmo, proporción y armonía, que como arquitecto había aprendido.

En otro apartado, Chávez argumentó, siguiendo a Dalcroze, que el ejercicio constante y progresivo de la interpretación rítmica de composiciones musicales conducía a la "concepción estética de formaciones rítmicas de conjuntos plásticos". ${ }^{120}$ Dichas actividades producirían "un efecto muy agradable" por la "correlación armoniosa de todos los elementos", en donde la divisa sería la persecución de la unidad (armonía, consonancia) en la diversidad (multiplicidad), lo que podía lograrse con un adecuado plan general y la educación de los sujetos que lo llevarían a cabo bajo esquemas de cooperación y coordinación: la recompensa era alcanzar "lo bueno y lo bello". ${ }^{121}$ Estas últimas palabras recuerdan mucho los propios preceptos que mantenía su hermano Ezequiel antes de su sistematización filosófica y, con mayor razón, durante y después de ella.

Esta noción de cuadros plásticos ejecutados por individuos o por grupos de ellos puede ser apreciada en la lámina que aquí se reproduce (Figura 4, arriba y en el medio), perteneciente también al lote de papeles del archivo particular de Samuel Chávez (sin firma y sin datación). Por la ausencia de firma, se supone que la lámina fue redibujada por Samuel Chávez con base en el libro de Dalcroze, "La Rythmique" (1916),122 que poseía en su biblioteca personal, en cuyas páginas 35-36 y 48-49 Dalcroze describe maneras diversas de saltar siguiendo secuencias rítmicas, como la presentada en la parte media de la Figura 4, que corresponde a la pauta rítmica de la primera forma de salto (arriba a la izquierda). En la parte inferior, se reproduce la secuencia correspondiente de Dalcroze de este primer salto, tal como aparece en dicho libro.

120 Chávez, "Lo que es la gimnasia", pp. 479.

121 Chávez, "Lo que es la gimnasia”, pp. 479-480.

122 Jaques-Dalcroze, La Rythmique. 

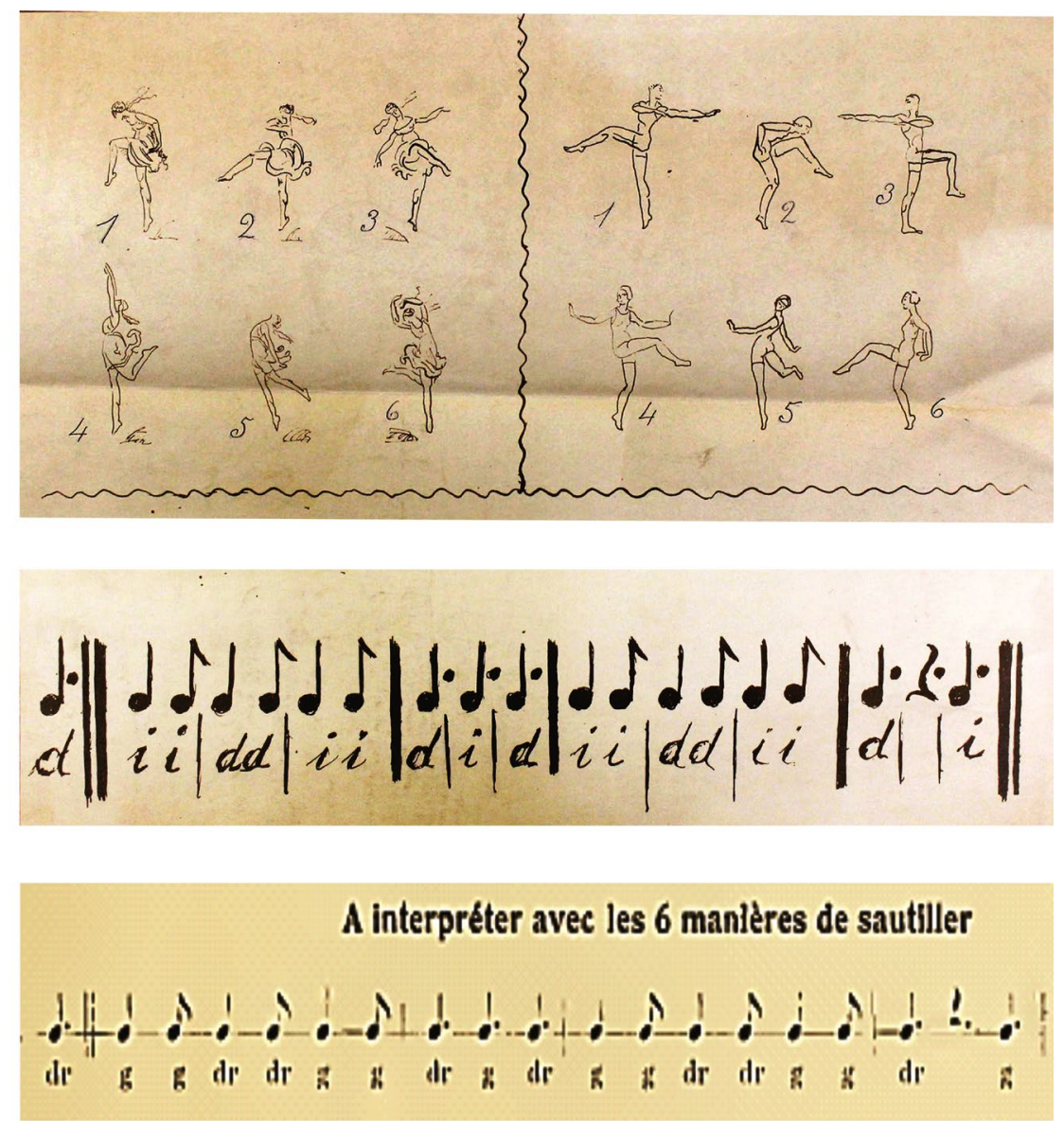

Figura 4: Arriba izq.: las 6 formas de saltar. Arriba der.: diversas formas de saltar. Parte media: secuencia rítmica de la primera forma de saltar. Abajo: secuencia original publicada por Dalcroze. Cortesía del APSChL, en proceso de catalogación; y Jaques-Dalcroze, La Rythmique, p. 35.

Poco antes de la publicación del ensayo sobre gimnasia rítmica, en 1917 se abrió un panorama distinto para Samuel, pues conoció a Antonia Mercé - mundialmente conocida como La Argentina-, bailarina de danza española que fue la sensación en su tiempo. De algún modo, Chávez, la bailarina (nacida en Argentina, pero de padres españoles) y el famoso compositor Manuel M. Ponce entraron en contacto. El día 22 de septiembre de 1917, Samuel registró en la Secretaría de Instrucción 
Pública y Bellas Artes, vigente hasta su desaparición efectiva en 1918, una obra mixta consistente en " 22 estructuras rítmicas musicales para el desarrollo de ejercicios de gimnasia rítmica". ${ }^{123} \mathrm{Al}$ parecer, con este material, Ponce compuso 16 preludios bailables en los que La Argentina se interesó a efectos de montar coreografías bailables con su arte. Sin embargo, Marcé tuvo que salir de México de manera intempestiva, llevándose consigo los preludios susodichos, que, al parecer, se extraviaron, dado que la bailarina afirmaba haberlos remitido a Ponce a través de interpósita persona, pero ésta negaba haberlos recibido. ${ }^{124}$

Por otro lado, se sabe que por lo menos desde 1918 Samuel comenzó a explorar de manera más profunda la música. Así lo revelan algunas láminas de su archivo particular, en las cuales consignó estar trabajando en aquel dispositivo musical para producir el ritmo, al que denominó pneumáfono, a lo que lo empujó la visión del potencial pedagógico de la gimnasia rítmica y su aplicación práctica en la educación artística. Por ello, redondeadas sus exploraciones, Chávez emprendió un segundo viaje a los Estados Unidos, con el propósito de registrar su invento en la Oficina de Patentes en Nueva York. No se sabe por qué en Estados Unidos, lo cierto es que partió el 24 de mayo de 1919 del puerto de Veracruz en el buque S. S. Esperanza, arribando a Nueva York el 2 de junio siguiente. ${ }^{125}$ Después de las gestiones, Samuel Chávez logró que su invento quedara registrado el 26 de diciembre de 1920, con el nombre de "pneumaphone bells". 126

Pero la puesta en práctica de la gimnasia rítmica no sólo la circunscribió Samuel Chávez a la composición de algunas estructuras rítmicas para artistas de la época, ni únicamente a su ejercicio personal, actividad que al parecer sólo practicaba a la sombra de la vista

123 AGN, Propiedad Artística y Literaria, Caja 309, Partitura musical: Estructuras rítmicas musicales para gimnasia, de Manuel M. Parra [sic: Ponce] y Samuel Chávez. Exp. 1075, Registro No. 341, fs. 1, 22 de septiembre de 1917.

124 El Pueblo (noviembre 1917), p. 4.

125 List or Manifest of Alien Passengers for the United States Immigration Officer at Port of Arrival, en línea: https://tinyurl.com/248xw5zw [05-07-2021].

126 Con el número 989, Clase I 5738 para "Drawings or Plastic Works of a Scientific or Technical Character", con dos copias entregadas el 27 de diciembre de 1920. Ver Catalogue of Copyright Entries, Part 4: Works of Art; Reproductions of a Work of Art; Drawings or Plastic Works of a Scientific or Technical Character; Photographs; Prints and Pictorial Illustrations, Volume 16, Issue 1, Washington: Government Printing Office, 1921, p. 28. 
pública, ${ }^{127}$ sino que intentó impulsarla en los niños, los maestros y los obreros a través de las escuelas que estaban bajo su supervisión como Inspector General de Dibujo y Labores Manuales de escuelas elementales y de las nocturnas para trabajadores, durante los gobiernos de Madero, Huerta y Carranza. ${ }^{128}$ Desafortunadamente, su éxito fue magro por la situación del país, aunque la gimnasia rítmica, algo desvirtuada, se logró introducir en una Escuela Elemental de Educación Física en 1923;129 asimismo, no se ha podido documentar si el pneumáfono llegó a superar su calidad de prototipo e implementarse en dichas escuelas. A pesar de ello, todo esto lo convirtió no únicamente en uno de los precursores de la danza moderna en México, ${ }^{130}$ sino en un personaje que procuró la transformación del país a través de una educación artística vanguardista.

\section{Conclusiones}

A partir de los objetivos que se abordaron en este artículo, se concluye que para Samuel Chávez el encuentro en Hellarau con una pedagogía revolucionaria en educación artística y con el creador de la gimnasia rítmica Émile Jaques-Dalcroze, significó un cambio tanto en su desarrollo personal y profesional, como en su inserción social en el marco de las políticas públicas de los gobiernos de la Revolución mexicana, en los que intentó fomentar, sin demasiada fortuna, la práctica de dicha gimnasia en las instituciones educativas que estaban a su cargo como inspector de escuelas. Asimismo, en su ensayo sobre gimnasia rítmica se observa todo un discurso sobre el cuerpo con el que pretendía sublimar la inmanente fugacidad del movimiento, trastocándola en ansia de trascendencia, lo que supuso transitar de un concepto de corporalidad física a un concepto de corporalidad espiritual (léase eurítmica), que a la luz del ensayo significaba acompasarse con el Ritmo Universal. Dicho de otra manera, se está en presencia, en el sistema de pensamiento y acción de Samuel, de un

127 Mariscal, “El arquitecto”, p. 14.

${ }^{128}$ AGN, Instrucción Pública y Bellas Artes, Vol. 292, Exp. 25, 12 fs., 27 de noviembre y 2 de diciembre de 1913.

129 Chávez González, "La introducción”, pp. 148-161.

130 Raquel Tibol, "Samuel Chávez y Carlos Mérida, precursores de la danza moderna en México": Revista Proceso, 426 (29 de diciembre de 1984). 
sistema de pares complementarios que, de una u otra manera, remitían a la relación entre lo inmanente y lo trascendente, entre la corporalidad física y transitoria (sensaciones) y la espiritualidad duradera (intuiciones), y entre la finitud/tangibilidad y la infinitud/intangibilidad.

Así, la exploración del recurso del ritmo le permitió a Samuel aproximarse a las reflexiones psicológicas y místico-religiosas que su hermano Ezequiel mantenía sobre el cuerpo, quien abogaba por una armonía universal en que el sujeto se fundiera con lo Infinito, y que por su lado Vasconcelos mantenía sobre el ritmo y su monismo estético, que tendía al Absoluto, aspectos que en distinto momento ejercieron cierta influencia en las políticas públicas sobre educación artística de los gobiernos de Madero, Huerta, Carranza y Obregón. En Samuel Chávez se evidencia una genuina intención de despertar en los educandos, así fueran los niños o los obreros e, incluso, los maestros, "una primera emoción artística frente a la naturaleza circundante".131

A pesar de las múltiples circunstancias que jugaron en contra de su ilusión, desde su marco cognitivo, epistémico y hasta religioso, Samuel Chávez pretendió contribuir a la felicidad del país, de sus niños, sus obreros, sus maestros, por medio de su trinchera cultural, pues estaba "dispuesto a luchar [...] por nosotros y por nuestra pobre patria en la única forma que puede ser eficaz[,] aunque es la más difícil ahora[:] haciendo esfuerzos por la cultura", 132 y a través de su firme convicción en las bondades que para aquéllos proporcionaba la educación artística.

131 Povedano Marrugat, Arte, p. 403.

132 AHUNAM, FEACH, Asuntos personales, Correspondencia familiar, Caja 117, Exp. 39, Doc. 35, 5 de marzo de 1913. Las negritas son nuestras. 